\title{
Assessment of RC Tall \& Multi Storey Building using Software Mechanism such as Staadpro and CSI-Etabs: A Review
}

\author{
Arvind Vishwakarma ${ }^{1}$, Lalit Balhar ${ }^{2}$
}

Department of Civil Engineering, Oriental University Indore, M.P., 453555 India

Corresponding Author Email: ${ }^{1,}$ visharvind28@ gmail.com, ${ }^{2}$ lalitbalhar@ orientaluniversity.in

\begin{abstract}
Staadpro and E-tabs are most versatile used software in Indian Market recently. Many of the researchers who are working in different companies and organization make efficient use of these software. The proposal and checked procedure of Government body are also willing to check by staadpro and CSI-Etabs software. With the time frame, it is easy to get result through software rather than the manual calculation in the current scenario. The economical design of a building is main aim of a Civil Engineer so a different trial has been made to reach out to extent of design standards using these software's. The current project deals with the examiner of Tall \& Multi storey RCC building frame design on account of dynamic loads acting in the lateral's direction such as earthquake and wind and the software used for the study is Staadpro and csi-Etabs. The main objective is to test the accuracy of the software accompanied with goal to make buildings with resistance free from the failures. It provides favorable output to make the technical fit and serviceable buildings.
\end{abstract}

Keywords: Software, Staadpro, CSI-Etabs, Tall \& Multi storey RCC building design.

\section{Introduction}

The analysis for any activity or RCC frames or any other structures is generally based on time history. In past decades the most of buildings with covering vast area were designed manually by highly qualified and experienced structural designers. The population previously low but with growing increase of people in numbers, there is direct affect in terms of the load and revisiting capacity of a building. Under this situation the more focus on the design criteria of buildings is required where high-rise design criteria, the soil and foundation are mostly taken into consideration. Thus, at present the design process is done by means of various load calculation software such as staadpro and ETABS. The manual calculation of the design of structures demands lot of time and prone of errors. With the development of these software, it made more comfortable and with ease for a human being by reducing time and human efforts in building design. This software receive utility at different approach of earthquake analysis such as TMA, RS etc. The result parameters are under taken for the calculation of lateral displacement, storey drift etc. parameters with already encoded time intervals been provided with the specific arrival time and damping factor. In staadpro and E-TABS software, the computation is 
carried out using IS codes inbuilt. This software provides very accurate as well as precise results than manual calculation and they are very beneficial.

\section{Literature Review}

A few recent scientific literatures with basic touch with software mechanics of civil engineering structural point of view in staadpro and csi-etabs are considered for the study. Staadpro is one of the leading structural design software. In this project, we analyze a $G+8$ building to find shear forces, bending moments, deflections, and reinforcement details for building structural elements (such as beams, columns, and slabs). Staadpro software Suitable for $G+8$ structures compared to Etabs software. The time period and base shift of the regular and irregular structure in the etabs software is twice that in the staadpro software. The Literatures are discussed as follows:

Jajoriya et. al. [1] worked on the different arrangement of four pile groups for group action and modeling considering weak and expansive soil such as clayey soil having a weaker bearing capacity and was examined for the utility of pile groups. In study, spacing between pile groups were taken as $2.5 \mathrm{D}$ and 3.5D (D-Diameter of pile); with $0.8 \mathrm{D}$ as the diameter of four pile group with different pile arrangements such as rectangular, square, staggered; diamond 1 and diamond 2. Analysis for different shapes of pile groups were done by response spectrum method using software approach. Displacement, Shear force and bending moment and three types of stresses are evaluated under the analysis of models. The authors concluded that over than square and rectangular pattern the diamond shape is also adopted for the group but the staggered shape are not predominant resisted the axial force through its arrangements.

Vishwakarma and Maru [2] investigated a new concept of building behavior, that is, the criteria for human comfort in a high-rise structure by response of wind. The response is recorded in the form of the peak acceleration estimation using the IS code 1 approach of IS 875 (part 3): 2015 which consider four different frame tubes of a high-rise structure with circular cross section from the top view. The storey taken as $\mathrm{G}+20,30,40$ \& 50 with different conditions, i.e. normal slab, secondary beam, wafer slab and ribbed slab are taken with a typical round floor with a diameter of $50 \mathrm{~m}$. The ETABS-2013 software is used in it with considered parameter namely, the maximum displacement which is estimated by dynamic building wind analysis using the corrosion factor method. Using maximum bias, the Acceleration Peak can be calculated using IS-875 (Part 3); 2015 for various structural conditions of scaffold pipes and construction modes. The peak acceleration obtained in the analysis is then compared with the reference data. Result showed that $\mathrm{G}+20,30,40$ are satisfactory result in human response but in $\mathrm{G}+50$ some changes are required to satisfy the human comfort range.

Sivaji et. al. [3] analyzed a multi storey building by taking software staad.pro \& csietabs. The design of building is based on the codel approach followed by IS 456 with manual calculation. The load used in the analysis are dead load (IS875-1987 part1), live load (IS875-1987 part2), wind load (IS8751987 part 3), seismic load (IS1893-1984 part1) and 25 load combinations were considered as 
per the IS875 (part5)-1987 code book. The beams, columns and slabs were designed using software and by manual procedure, reinforcement details are compared. The foundation is designed by using STAAD Foundation software.

Kalim et al. [4] considered a multi-storey building and code approach of Is 456 and Indian wind codes IS 875part I, II, III. The researchers found many similarities and flexibility in both software are topic based on this study with the help of fourteen storey. The structure consists of dimension of beam and column is same through the cross sections. The software basic parameters are studied in it which is found approx similar behavior.

The authors emphasized on load calculations and analysis. The Staadpro and etabs based analysis was carried out with the principle involve civil engineering aspect to design a safe and economical structure. To solve much more complex and large structures. Staadpro features - modern user interface, visualization tools, and powerful analysis and design engines with dynamic analysis capabilities. Staadpro is the professional's choice, from model generation, analysis and design to visualization and validation of results. Etabs is also the leading design software currently used by many designers. The analyzed the regular structure using the etabs development software. Etabs gave a smaller steel area compared to the Staad Pro.

Balhar et al [5] The study of this paper is based on the staad pro based analysis using a multistory building is modeled. The three methods are used for the earthquake analysis. The methods are ES, RSA \& THA. The prior load acr taken in it is gravity and dynamic loads, analyzed using analysis. It has been observed that lateral displacement, floor displacement and floor drift in the construction of flat slabs are more than conventional slab construction.

Balhar et al [6] examined the behavior of multi-storey buildings with conventional radar plates, flat plates. The characteristics of buildings were observed under seismic conditions. The obtained result values were based on floor drift, lateral displacement, seismic base shear, floor displacement. The paper concluded that it is important to analyze behavior of buildings under seismic response in order to see what changes will occur for a conventional RC frame building, a flat-plate building and a shear wall, respectively.

Charan et al. [7] examined changes of twist alongside the stature of structure on soak slant to research the part of topographic conditions in dispersion example of wind constrain. The investigation of a $\mathrm{G}+5$ and $\mathrm{G}+11$ storey $\mathrm{RCC}$ expanding on fluctuating slant points i.e., $0^{\circ}$, $15^{\circ}, 20^{\circ}$ was examined and contrasted and the same on the level ground, by using SAP 2000 software v16. In display look into think about parameter such as float based on storey wise and other parameters was displacement, which were basically broke down to assessment on the inclined ground were contrasted and diverse slants and distinctive statures.

Reddy et al [8] targeted to conduct a detailed analysis of the etabs and staad pro modeling tools that were used to analyze and design a rectangular plan with a vertical regular and rectangular plan with a vertical geometrically irregular multi-storey building. This study focuses on identifying the benefits of using etabs over current practice of staad pro versions. The authors observed that etabs is 
more user-friendly, accurate, compatible for analysis of design results and many other advantages that will be discussed in this study over staadpro. Similar response is reported by Manikanta et al [9] conducted experiment on a comparative analysis of the results obtained in the design of a conventional and irregular (according to IS 1893) multi-storey building structure when designing using the Staadpro and etabs software separately with a target to compare the design and analysis of a high-rise building $(\mathrm{G}+8)$ using the software Staadpro and etabs. After completing the design of the structure in both software products, they observe that the design results show $0.4-0.5 \%$ more steel in etabs. By comparing the results of the two structures (regular and irregular), the conventional framing element shows the maximum bending moments, shear forces and axial forces for different loading conditions in both programs.

Bedi et. al. [10] The researcher proposed to analyze and conduct a comparative study of rcc framework structures using Staad.Pro, etabs and sap. The proposed research analysis, it is conclude that Staadpro is much more effective. Strong derivatives compared to etabs and sap. The maximum difference between the Staad.Pro, etabs and sap values.

Subramani and Murali [11] obtained the execution of a multi-storey structural with $\mathrm{G}+10$ storey building. The structure is performed under static and dynamic analysis. The different mode was using ETABS software. High-rise performance analysis for distinctive modes is performed with the aim of identifying the most reliable function of the gadget and truss using side loads. The analysis of the temporal history for statistics of floor movement in the version of the ten-story building is carried out. The floor comes with flow and base shear for static and dynamic loading. Based on the results the effective character of a building with outriggers is evaluated. Describes the structural diagram of a similar 10-storey building that uses common characteristics based on seismic and wind strategies.

Patil, et. al. [12] The research paper deals with the SAP2000 software. It is used to examine the concrete \& steel structures, parking garages, skyscrapers, his rise structure in different levels. Under sap a structure is modeled have a G+3 storey framed building. The outputs are in the terms of max. Shear forces, bending moments \& maximum displacement of the structure are computed. The IS456 \& SP16 provision are adopted for the structural elements are designed.

Manikanta [13] This study is an attempt to investigate and compare the results for building with different stories. A regular plan building with $\mathrm{G}+5, \mathrm{G}+10$ and $\mathrm{G}+15$ stories have been considered in this study. It has been observed that buildings with less no of stories when analyzed by STAAD-PRO give conservative results and buildings with high number of stories when analyzed by ETAB produced conservative results.

Sahu et. al. [14]. The purposes of researchers are to analyze and construct the main building G+3 storey building using SAP 2000. Includes planning on how to classify loads and full details of the SAP 2000 layout. research used in SAP 2000 image analysis of stateless state according to Indian Model Law. SAP 2000 demonstrates a person's status including research status, research tools, powerful integration of analysis and the details of its 
core values. From quantitative analysis, the two-dimensional tables and confirming the research and structure to results, and visual and validated visualizations, SAP 2000 is the inaccuracies of the program and our results. The accuracy is more in the result gets.

professor's choice. We begin by examining

Table1 Comparisons Staadpro and CSI- Etabs

\begin{tabular}{|c|c|c|c|}
\hline S.No. & $\begin{array}{l}\text { Properties/ } \\
\text { description }\end{array}$ & Staad.Pro & CSI- Etabs \\
\hline 1 & $\begin{array}{l}\text { Latest } \\
\text { version }\end{array}$ & StaadproV8i & ETABS 2020 \\
\hline 2 & Developed by & $\begin{array}{l}\text { Development Research Engineers } \\
\text { International in 1997. Research } \\
\text { Engineers International was bought } \\
\text { by Bentley Systems IN Yorba } \\
\text { Linda, CA in 2005. . }\end{array}$ & $\begin{array}{l}\text { Developed by Computers and } \\
\text { Structures, Inc. (CSI) } \\
\text { America. }\end{array}$ \\
\hline 3 & Flexibility & $\begin{array}{l}\text { As per discussion and use of } \\
\text { different users staad.pro is quite } \\
\text { less flexible as compare to csi-etabs }\end{array}$ & $\begin{array}{l}\text { As per discussion and use of different } \\
\text { users staadpro is more flexible as } \\
\text { compare to csi-etabs }\end{array}$ \\
\hline 4 & Output gets & $\begin{array}{l}\text { Displacements, story shear, story } \\
\text { drift, stress, moments etc }\end{array}$ & $\begin{array}{l}\text { Displacements, story shear, stress, } \\
\text { moments etc } \\
\text { But drift are shown with unit less } \\
\text { parameters in it, latter it is converted } \\
\text { into unit quantity with the help of } \\
\text { factors. }\end{array}$ \\
\hline 5 & Stresses & $\begin{array}{l}\text { Absolute, tresa, monmesko types } \\
\text { stress shown directly on it }\end{array}$ & $\begin{array}{lll}\text { Absolute and maximum } & \text { stress } \\
\text { developed mainly and other } & \text { stress } \\
\text { given some unique code forms. } & \end{array}$ \\
\hline 6 & $\begin{array}{l}\text { Result } \\
\text { display }\end{array}$ & $\begin{array}{l}\text { Tabulated but less interface } \\
\text { clearificance as compare to etabs, } \\
\text { import to excel also. }\end{array}$ & $\begin{array}{l}\text { Tabulated and easy grip the result and } \\
\text { import in pdf. }\end{array}$ \\
\hline 7 & $\begin{array}{l}\text { Orientation } \\
\text { of task bar }\end{array}$ & $\begin{array}{l}\text { Oriental is good and all task bar is } \\
\text { display on the top as well left side } \\
\text { of screen }\end{array}$ & $\begin{array}{l}\text { Oriental is more better and all task bar } \\
\text { is display on the top as well left side of } \\
\text { screen, }\end{array}$ \\
\hline 8 & $\begin{array}{l}\text { Uses in Govt. } \\
\text { approval } \\
\text { project }\end{array}$ & $\begin{array}{l}\text { As per MP govt. project survey } \\
\text { max. Department are use Staad.pro } \\
\text { design as approval. }\end{array}$ & $\begin{array}{l}\text { Some govt. are aware about the etabs } \\
\text { and need to aware more }\end{array}$ \\
\hline 9 & $\begin{array}{l}\text { Load } \\
\text { combination }\end{array}$ & $\begin{array}{l}\text { Load combination is assigned by } \\
\text { user }\end{array}$ & $\begin{array}{l}\text { Load combination is assigned by user } \\
\text { as well as it is by default is there in the } \\
\text { software also. }\end{array}$ \\
\hline 10 & User friendly & $\begin{array}{l}\text { Both are nice and easy way to } \\
\text { operated }\end{array}$ & $\begin{array}{l}\text { Both are nice and easy way to } \\
\text { operated but overall etabs prefer more } \\
\text { versatile }\end{array}$ \\
\hline 11 & $\begin{array}{l}\text { Foundation } \\
\text { modeling }\end{array}$ & $\begin{array}{l}\text { An extra software is there ie. Staad } \\
\text { foundation but we can modeled to } \\
\text { staad.pro also }\end{array}$ & $\begin{array}{l}\text { An extra software is there ie. SAFE } \\
\text { but we can modeled to Etabs also for } \\
\text { simple foundation }\end{array}$ \\
\hline 12 & Import file & Autocad file import in it & Autocad file import in it \\
\hline
\end{tabular}


Zhou et al. [15] in this project, in order to fully evaluate the structural behavior of the Sanghai International Design Center (SHIDC) in earthquake conditions, Noscad, Abaqus and execute-3d. It is used to perform analysis of elastoplastic, temporal history, numerical data results. It also worked on compared this results with vibration table test data, Noscad has a functional module for converting nonlinear analysis model to perform-3d and Abaqus. These models can be used directly in Abaqus or Perform-3d. By the transformation of the model, the seismic characteristics of SHIDC were fully investigated. The analysis gets the maximum drift between floors is within the limits as per Chinese code provisions. The reasonable failure sequence of the structural elements was obtained. This concludes the input energy dissipation is well in earthquake analysis. The structure is intact during frequent earthquake. The structure does not collapse during rare earthquakes. Based on this approach the task of this project has been completed.

Sabeer and Peera [16] the paper consist of irregularity of the structures. Plan Analysis with Vertical Geometrically Irregular Multistory Building using the static method of this research-oriented project is to explore in detail the modeling tools for structural analysis and design. Simulation comparison is implemented by STAAD. Comparing STAAD PRO and ETAB software results in different results that are difficult to understand and confusing at the time of boot parameter assignment and design. Based on the results of the calculation of the beams. Based on result it concluded etabs obtained smaller area of steel requirements compared to staad pro. The required column area in steel is the same for both programs, but in this case it is taken into account as a percentage of $0.3 \%$ to $0.5 \%$. Form the results of the calculation of the column; Since the required steel for the column forces is fashionable. The certain obtain problem is less than the minimal limit of the column steel (ie $0.85 \%$ ). steel obtained through both the software are almost equal.

\section{Prashanth. et. al. [17]}

Deals with irregularity impact on the structure as per codel approach used in IS 1893(PART-I) . The conventional design also taken in to the account. The relative study are based on the both types of software separately. The CSI-ETABS \& Staad is used under it. Manual calculation is also done in this project as per codel IS 456. The results shown that ETABS produced less steel area required compared to STAAD PRO. On comparing STAAD results with manual calculations it showed that Staad.pro gives conservative design results. This result is again confirmed in this study by comparing STAAD.Pro, Generate column design results due to the required steel for the column forces in this particular task is less than the minimum limit for the column steel (i.e. $0.8 \%$ ). The same amount of steel calculated by both programs.

\section{Gap of Study}

With multiple reviews \& study of most of the papers it has been analyzed that there have been following gape of study:

1). Comparison of the modeling of both the software's namely E-tabs \& Staadprois not done by using Time history Analysis. 
2). The use of shear wall \& without shear wall effect is also not taken into consideration during of analysis.

$3)$.The use of Comparison of different RCC \& composite frames modeling in software's has also not been analyzed.

4).The criteria of taking different soil Earthquake Zones are not being analyzed in both softwares.

5). Comparison of Flat slabs \& Conventional slabs using both the software have also found in the gape of study.

\section{Conclusions}

On the basis of compared the software of Staadpro and CSI-Etabs

1) Both software and equally predominating in their respective platforms.

2) Staadprois run by Bentley and CSIEtabs is run by CSI- America.

3) The output scenario both are gives immense results but somehow better result platform is obtained by CSIetabs.

4) The outputs are plotted and tabulated in terms of displacement, drift, shear and moments of the storey. But in case of Bentley staadpro the stresses are obtained in the form of different types such as absolute, von Masco, and tresca top and in etabs absolute and maximum stress are major concern by the different researchers.

5) The graphical results easily obtained in the csi-etabs software as compare to staad.pro.

6) Different structural form such as bracing, outrigger, shear wall, hull core, tube etc are easy way to construct in etabs as compare to staad.

7) Both software earthquake approach are anyslsed somehow by default in csi-etabs the alcentro earthquake is there for the time history analysis. For user friendly maximum researchers are used pushover and response spectrum method there project analysis.

\section{Conflict of Interest}

\section{The authors declare no conflict of interest.}

\section{References}

[1] Jajoriya, M., Khalotiya, D., \& Vishwakarma, A. Seismic Analysis of Pile Group with Different Variations in Dimensions and Parameters.

[2] Vishwakarma, A., \& Maru, S. (2019). Assessment on Human Comfort Criteria of Tall Building under Dynamic Wind Loading. International Journal of Innovative Technology and Exploring Engineering (IJITEE) ISSN, 2278-3075.

[3] Sivaji, A., Reddy N.M. Yeswanth T. K., (2019) "Analysis \& Design Of Multi-Story Building Using Staad Pro And E-Tabs" International Journal of Management, Technology And Engineering (IJMTE) Issue 1 ,Vol 9.

[4] Kalim, M., Rehman, A., Tyagi, B. S., (2018) "Comparative Study on Analysis and Design of Regular Configuration of Building by Staadproand Etabs" International Research Journal of Engineering and Technology (IRJET) 5 (3); 1794-1797. 
[5] Balhar, L., \& Vyas, D. J. (2019). Comparative Analysis of Flat slabs \& Conventional Rc slabs with and without Shear wall. International Research Journal of Engineering and Technology (IRJET) Issue, 1 .

[6] Balhar, L., \& Vyas, D. J. (2019). Review Paper on Comparative analysis of Flat slabs \& Conventional Rc slabs with and without Shear walll. International Research Journal of Engineering and Technology (IRJET)

Issue, 2.

[7] Charan R.S.S, Baraik, S., Venkata, G.R., (2018), "Wind Analysis of High-Rise Buildings Using Sap2000", International Journal of Civil Engineering and Technology (IJCIET), 9 (8).

[8] Reddy, S. V. B., \& Madhu, V. (2018). Comparative Study on Design Results of a Multi-storied Building using STAAD PRO and ETABS for Regular and Irregular Plan Configuration. International Journal of Applied Engineering Research,13(15), 12194-12201.

[9] Manikanta, K. V., \& Venkateswarlu, D. D. Comparative Study On Design Results Of A Multi-Storied Building Using STAAD Pro And ETABS For Regular And Irregular Plan Configuration. International Journal of Research Sciences and Advanced Engineering, 2(15), 204-215.

[10] Bedi, I., Sharma, G. Gupta, A., (2017) Comparative Study of RCC Frame Structures Using Staad.Pro, Etabs, And Sap. International journal of advance research in science \& Engineering . Issue 9,Vol 6.

[11] Subramni, T., \& Murali, K. (2018). Analytical Study of Tall Building with outtrigger system with respect to seismic and wind analysis using ETABS. Int $\mathbf{J}$ Eng Technol, 7(3.10), 77-82.

[12] Patil, R., Anoor, S., Desai, S., \& Kumar, M. (2017). Analysis and Design of Residential Building by Using SAP2000. IRJET, 4(5), 3-7.

[13] Manikanta, K. V., \& Venkateswarlu, D. D. Comparative Study On Design Results Of A Multi-Storied Building Using STAAD Pro And ETABS For Regular And Irregular Plan Configuration. International Journal of Research Sciences and Advanced Engineering, 2(15), 204-215.

[14] Sahu, A., Bose R. Mukherjee, I., and Sahil, Mondal, H., (2016) "Design \& analysis of multi-storied building using sap 2000" Journal of Basic and Applied Engineering Research 3 (11), 991-995.

[15] Zhou, D., Guo, C., Wu, X., \& Zhang, B. (2016). Seismic Evaluation of a Multitower Connected Building by Using Three Software Programs with Experimental Verification. Shock and Vibration, 2016.

[16] Sabeer, M., Peera D., (2015) "Comparison Design Result Of Rcc Building Using Staad And Etabs Software" International Journal of Innovative Research in Advanced Engineering (IJIRAE) Issue 8, Volume 2.

[17] Prashanth, P., Anshuman, S., Pandey, R. K., \& Herbert, A. (2012). Comparison of design results of a Structure designed using STAAD and ETABS Software. International Journal of Civil \& Structural Engineering, 2(3), 869-875. 